\title{
Micropuncture Measurement of Lung Microvascular Pressure Profile in 3- to 4-Week- Old Rabbits
}

\author{
J. USHA RAJ, P. CHEN, AND L. NAVAZO \\ Department of Pediatrics, Harbor-UCLA Medical Center, UCLA School of Medicine, Torrance, CA 90509
}

\begin{abstract}
We have reported the longitudinal distribution of vascular resistance in the three segments (arteries, microvessels, and veins) of the pulmonary circulation of adult rabbits (J Appl Physiol 60:539-545, 1986). To determine the longitudinal distribution of vascular resistance in lungs of younger animals, we measured microvascular pressures in the subpleural microcirculation in nine isolated blood perfused lungs of 3- to 4-wk-old rabbits. We used micropipettes and the servonull pressure measuring system to directly measure pressures in 20-50 $\mu \mathrm{m}$ diameter subpleural arterioles and venules. We also measured pulmonary arterial and left atrial pressures and lung blood flow. To determine the influence of vascular tone on segmental vascular resistance, in four lungs we measured microvascular pressures both before and after paralyzing the vasculature with papaverine. We found that $51 \%$ of the total pressure drop in the pulmonary circulation was in arteries, $\mathbf{2 4 . 5 \%}$ in microvessels, and $\mathbf{2 4 . 5 \%}$ in veins. Vascular tone contributed minimally to baseline arterial resistance. The greater arterial and venous resistance in lungs of 3- to 4wk-old rabbits as compared to that in adult rabbits is probably due to differences in vessel geometry. (Pediatr Res 20: 1107-1111, 1986)
\end{abstract}

Various methods have been used to determine the contribution of the three longitudinal segments of the pulmonary vasculature, i.e. the pulmonary arteries, microvessels, and veins to the total vascular resistance in the lung (1-4). Recently, with the development of the technique of lung micropuncture, it has been possible to measure directly microvascular pressures in the subpleural microcirculation. Using this method, in the isolated dog lung, Bhattacharya and coworkers $(5,6)$ found that the major site of resistance to blood flow was the middle segment, i.e. microvessels $<20 \mu \mathrm{m}$ in diameter. Using the same technique in the adult rabbit lung, we found that $\sim 60 \%$ of the total arteriovenous pressure drop occurs in vessels $<20 \mu \mathrm{m}$ in diameter, $\sim 33 \%$ occurs in arteries and only $\sim 7 \%$ occurs in veins (7). In the adult rabbits we had eliminated vascular smooth muscle tone in the lungs by paralyzing the vessels with papaverine.

All the estimates of segmental vascular resistance in the lungs have been in lungs from adult animals. There are several reasons why the longitudinal distribution of vascular resistance in the lung is likely to be different in the younger animal. The high pulmonary vascular resistance in the fetus $(8,9)$ falls dramatically at birth $(10,11)$ but does not reach the low adult value until 36 months of age (12). Vascular resistance in the lung is high in

Received March 5, 1986; accepted June 5, 1986.

Address reprint requests to J. Usha Raj, Harbor-UCLA Medical Center, 1000 West Carson Strect, A-17, Torrance, CA 90509.

This work was supported in part by Grants from the National Institutes of Health HL34606 and the American Lung Association of Los Angeles County. early life partly due to a higher basal vasomotor tone (13) and in part due to differences in the morphology of the pulmonary vasculature (14).

In this study, using an isolated blood perfused lung preparation and the technique of lung micropuncture, we describe the distribution of vascular resistance in the pulmonary arteries, microvessels and veins in 3- to 4-wk old rabbits.

\section{METHODS}

Isolated lung preparation. We used the lungs of nine 3- to 4wk-old rabbits whose body weight averaged $910 \pm 150 \mathrm{~g}$. The rabbits received $25 \mathrm{mg} / \mathrm{kg}$ body weight of pentobarbital sodium anesthesia via an ear vein, after which we inserted catheters into the carotid artery and jugular vein and tied an endotracheal tube into the trachea. Immediately after placement of the venous catheter, we infused $20 \mathrm{ml} / \mathrm{kg}$ body weight of a plasma expander intravenously [ $5 \%$ dextran (mol wt. 70,000, Sigma Chemicals, St. Louis, MO) in Ringers lactate solution] to prevent anesthesia induced systemic hypotension which may result in the release of vasoactive agents into the circulation. The rabbits were allowed to breathe $100 \%$ oxygen for at least $15 \mathrm{~min}$ prior to injection of heparin (Elkins-Sinn, Inc., Cherryhill, NJ) $1000 \mathrm{IU} / \mathrm{kg}$ body weight intravenously, and rapid exsanguination through the carotid artery. We collected the drained blood to prime the perfusion circuit. To expose the lungs we cut away the anterior chest wall and sternum, and wrapped plastic sheets around the cut ends of the ribs so that the jagged bone ends would not tear the lung surface. Extreme care was taken not to touch the lung surfaces, as the pleura is very thin and easily torn. Plastic cannulas (ID $1 / 8$ inch, OD $3 / 16$ inch) filled with $5 \%$ dextran solution, were tied into the pulmonary artery via the right ventricle and into the left atrium via the left ventricle. Cannulation of the pulmonary artery was done with the vessel submerged in saline to prevent air bubbles from entering the lungs. We ligated the ductus arteriosus and the aorta and placed a suture around the ventricles to occlude their lumen. The thorax was kept in a supine position during perfusion of the lungs. The average time interval from the death of the rabbit to perfusion of the lungs was $15 \mathrm{~min}$.

We filled the perfusion circuit (Fig. 1) with approximately 200 $\mathrm{ml}$ of blood. Blood from donor rabbits was added to the amount exsanguinated from the experimental rabbit to make up the final volume. The hematocrit of the rabbits prior to volume expansion averaged $28.4 \pm 4.0 \%$ (SD) and that of the perfusate was $23.0 \pm$ $5.2 \%$. We added heparin to make a final concentration of $30 \mathrm{IU}$ heparin $/ \mathrm{ml}$ of blood. The $\mathrm{pH}$ of the blood was adjusted to 7.40 to 7.45 whenever necessary with the addition of sodium bicarbonate. We measured the $\mathrm{pH}, \mathrm{pO}_{2}, \mathrm{pCO}_{2}$, and hematocrit of the blood at the beginning of the experiments and at 15 -min intervals. We monitored blood glucose concentration by Dextrostix every $30 \mathrm{~min}$ and kept blood glucose between $90-130 \mathrm{mg} / 100$ $\mathrm{ml}$ by the periodic addition of $50 \%$ glucose in water. 


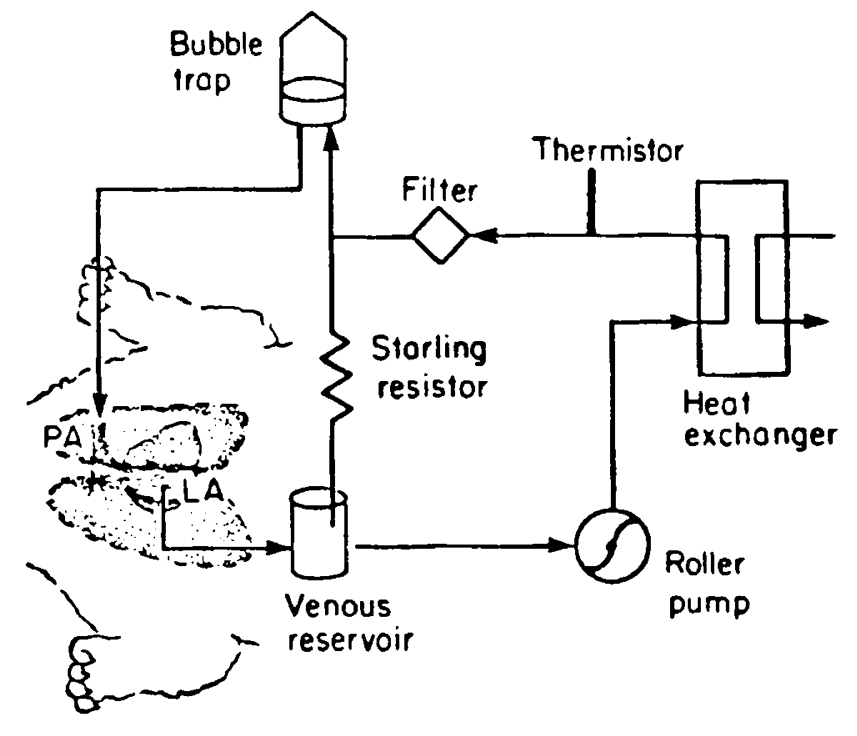

Fig. 1. Perfusion circuit for rabbit lungs. Blood is warmed, filtered, and degassed before entering the lungs. A Starling resistor prevents pressures from rising $>30 \mathrm{~cm} \mathrm{H}_{2} \mathrm{O}$ in the circuit.

A roller pump (integral variable drive, Cole Parmer, Chicago, IL) circulated blood through the pulmonary artery into the lungs and back from the pulmonary veins into a venous reservoir. The temperature of the blood was kept between $38-39^{\circ} \mathrm{C}$ by a heat exchanger (Miniprine, Travenol Labs) in the circuit. A thermistor probe placed at the outlet of the heat exchanger allowed continuous monitoring of the temperature. A microfilter (Ultipore, Pall Biomedical, Easthills, NY) placed in the circuit before the pulmonary artery filtered clots and bubbles and a bubble trap in the circuit acted as a depulsator. A Starling resistor prevented pressure from rising above $30 \mathrm{~cm} \mathrm{H}_{2} \mathrm{O}$ within the circuit. We continuously measured pulmonary arterial and left atrial pressures with pressure transducers (Gould Statham P23) that were connected to polyethylene tubing, the tips of which were located in the pulmonary arterial and left atrial cannulas. Zero reference level for vascular pressures was the top surface of the lung (the site of all micropunctures). Left atrial pressure was set by adjusting the height of the venous reservoir; the pulmonary arterial pressure was controlled by adjusting blood flow. We calibrated flow rate from the roller pump by timed collections of outflow.

Initially, we started perfusion at a very low flow rate with the lungs deflated. We then hand-ventilated the lungs at $20 / 5 \mathrm{~cm}$ $\mathrm{H}_{2} \mathrm{O}$ airway pressures (inspiratory and expiratory) with a gas mixture containing $94 \% \mathrm{O}_{2}$ and $6 \% \mathrm{CO}_{2}$ for $3-5 \mathrm{~min}$, followed by a sustained inflation pressure of $6 \mathrm{~cm} \mathrm{H}_{2} \mathrm{O}$ throughout the experiments. We chose this gas mixture so that we could maintain blood $\mathrm{pO}_{2}>200$ torr and $\mathrm{pCO}_{2}$ between $35-45$ torr. With a high blood $\mathrm{pO}_{2}$ we could be certain that there was no hypoxic vasoconstriction-the pulmonary vasculature of the rabbit is very reactive and likely to constrict when blood $\mathrm{pO}_{2}<100$ torr. We adjusted blood flow to maintain pulmonary artery pressure between $20-22 \mathrm{~cm} \mathrm{H}_{2} \mathrm{O}$, and adjusted the height of the venous reservoir to maintain left atrial pressure at $8 \mathrm{~cm} \mathrm{H} \mathrm{H}_{2} \mathrm{O}$. Vascular pressures and blood flow became stable within $15 \mathrm{~min}$. All lungs were perfused under zone III conditions (15), i.e. the left atrial pressure was kept greater than airway pressure in all regions of the lung. Once established, blood flow was kept constant for the rest of the experiment.

Microvascular pressure measurements. Microvascular pressure measurements were made using glass micropipettes and the servonull system for pressure measurement described by Bhattacharya and Staub (5). We used a pipette puller (Vertical pipette puller model 700D, David Kopf, Tujunga, CA) to make micropipettes from glass tubing (ID 0.0205 inch, OD 0.036 inch,
Drummond Scientific Co., Broomall, PA) and beveled the tip to a diameter ranging from $2-4 \mu \mathrm{m}$ on a pipette beveller (Diamond Abrasive plate, David Kopf). We filled the pipette with $1.2 \mathrm{M}$ $\mathrm{NaCl}$ solution colored with green dye (Guinea green) and connected it to a servonulling pressure measuring system (Model 4A, Instruments for Physiology and Medicine, San Diego, CA). The dye enabled us to see the tip of the pipette and to perform a dye flow test during micropuncture. To facilitate micropuncture of the lung, we stabilized the lung surface with a metal ring (attached to a stand on a firm base) placed lightly on the pleura. The ring also held a pool of normal saline on the lung surface for obtaining the zero reference pressure. In accordance with the principles of the servonull pressure measuring system, a pressure measurement is obtained only when the pipette tip lies freely in liquid and the electrical circuit is complete (16).

We viewed the lung surface through a stereomicroscope (Zeiss, Oberkochen, West Germany) at $\times 80$ or $\times 120$ magnification with illumination from a cold light source (Intralux 5000, American Volpi, Auburn, NJ). Subpleural arterioles, ranging from 10-100 $\mu \mathrm{m}$ in diameter are numerous and easily visible all over the lung surface, especially near the lung edges; venules are less numerous on the lung surface, but could be visualized on the mediastinal or diaphragmatic surfaces of the lung. We measured pressures in 20-50 $\mu \mathrm{m}$ diameter arterioles and venules by micropuncture and chose these sites for microvascular pressure measurements as it permits us to compartmentalize the pulmonary circulation into three segments; arterial segment is from the pulmonary artery to the $20 \mu \mathrm{m}$ arteriole, microvascular segment is between the 20 $\mu \mathrm{m}$ arteriole and venule, and venous segment is from the $20 \mu \mathrm{m}$ venule to the left atrium. We identified venules by observing the flow of red blood cells from small vessels into larger ones; for arterioles blood flow occurred from large vessels into smaller ones. We accepted microvascular pressure measurements (Fig. 2) only if they fulfilled the following criteria. 1) Reproducible zero reference pressure was obtained both before and after the

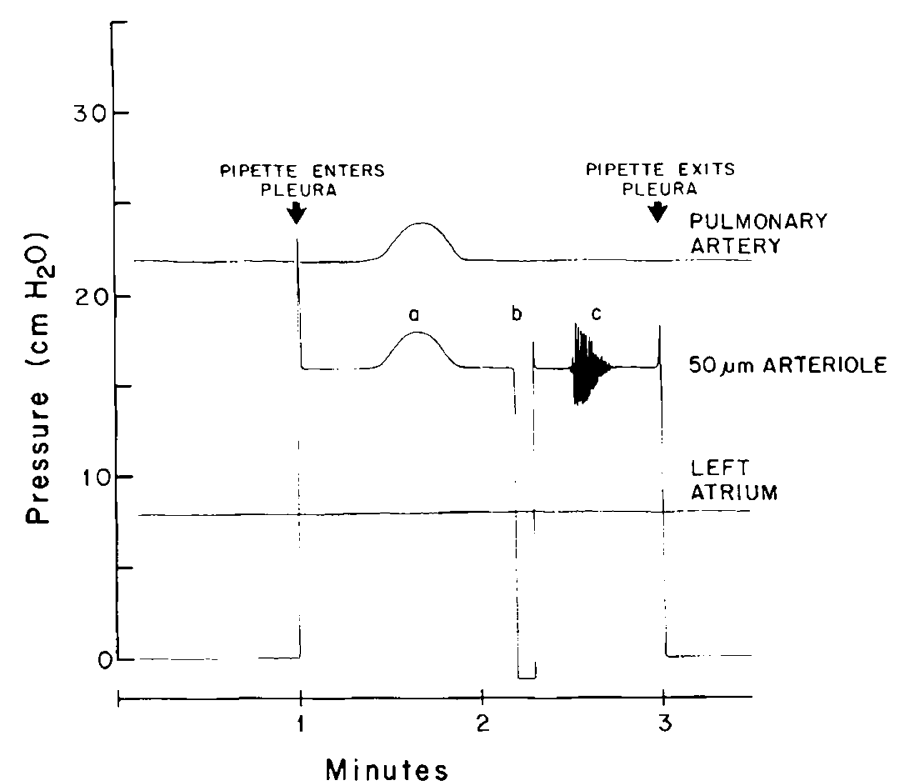

Fig. 2. Three-min pressure tracing. A $50-\mu \mathrm{m}$ arteriole was punctured and a stable pressure recorded for $2 \mathrm{~min}$. Three criteria for valid pressure measurements are shown here. $a$, when pulmonary artery pressure is raised transiently by increasing blood flow, microvascular pressure follows closely, returning to baseline afterward; $b$, when dye is injected through the pipette into the arteriole, it is seen to be rapidly washed out by the flowing blood. During injection the pressure tracing is lost transiently; $c$, on increasing the gain of the Servonull system, the pen goes into oscillations, returning to baseline when gain is lowered. This indicates that the pipette tip is lying freely in liquid. 
pressure measurement; 2) an immediate response in the microvascular pressure tracing when either the pulmonary artery or left atrial pressure was perturbed; 3) immediate washout of injected dye from the pipette by the flowing blood, indicating that the pipette tip was lying freely in the lumen; 4) a pressure measurement that was independent of small changes in the optimal servonull gain setting, which indicated that the pipette tip was lying freely in liquid.

Experimental protocol. With the nine lungs perfused with 145 $\pm 18 \mathrm{ml} \mathrm{blood} / \mathrm{kg}$ body weight $/ \mathrm{min}$, pulmonary artery and left atrial pressures were $21.8 \pm 2.3$ and $7.9 \pm 0.6 \mathrm{~cm} \mathrm{H}_{2} \mathrm{O}$, respectively. The cardiac output of adult rabbits was reported to be around $200 \mathrm{ml} / \mathrm{kg}$ body weight $/ \mathrm{min}$ (17). Microvascular pressures were measured by lung micropuncture.

In four of the nine lungs, after initial microvascular pressure measurements were obtained, papaverine was added to the perfusate to a concentration of $70 \mu \mathrm{g} / \mathrm{ml}$ blood. This concentration will effectively paralyze the pulmonary vasculature in the rabbit (18). Blood flow in these lungs averaged $133 \pm 31 \mathrm{ml} / \mathrm{kg}$ body weight $/ \mathrm{min}$. The mean pulmonary artery pressure of $21.0 \pm 1.8$ $\mathrm{cm} \mathrm{H}_{2} \mathrm{O}$ prior to the addition of papaverine fell to $19.8 \pm 1.3$ $\mathrm{cm} \mathrm{H}_{2} \mathrm{O}$ after paralysis of the vasculature. Left atrial pressure was constant at $8.0 \pm 0.0 \mathrm{~cm} \mathrm{H}_{2} \mathrm{O}$. Microvascular pressures were measured again.

Lung water measurements. We assessed the rate of weight gain in the lungs during perfusion by observing the rate of fluid loss from the venous reservoir. As there was negligible change in the level of blood in the reservoir, we confirmed that the lungs had not gained weight by weighing the lungs at the end of the experiments after allowing blood to drain out, then weighing them again after drying them in an oven for $72 \mathrm{~h}$ at $65-75^{\circ} \mathrm{C}$. This allowed us to calculate lung wet to dry weight ratio.

Analysis of data. All data are expressed as means \pm SD. We used the paired $t$ test for all paired comparisons and the analysis of variance for multiple comparisons, and accepted a $p$ value of $<0.05$ as indicative of significance.

\section{RESULTS}

The initial perfusate hematocrit was $23.0 \pm 5.2 \%$ and remained constant throughout the experiments. The $\mathrm{pH}$ of the perfusate was $7.43 \pm 0.06, \mathrm{pCO}_{2}$ was $38 \pm 8$ torr, and $\mathrm{pO}_{2}$ was $244 \pm 92$ torr. The wet to dry weight ratio of the lungs at the end of perfusion was $4.6 \pm 0.8$. The wet to dry weight ratio of five normal, nonperfused 3- to 4 -wk old rabbit lungs averaged $4.4 \pm$ 0.6 .

Pulmonary microvascular pressure profile in 3- to 4-wk-old rabbits. The total pressure drop across the pulmonary circulation was $13.9 \pm 2.2 \mathrm{~cm} \mathrm{H}_{2} \mathrm{O}$ and the calculated pulmonary vascular resistance was $0.096 \pm 0.01 \mathrm{~cm} \mathrm{H} \mathrm{H}_{2} \mathrm{O} \cdot \mathrm{min} \cdot \mathrm{ml}^{-1} \cdot \mathrm{kg}$ (Table 1). The pressure drop across the arterial segment was $7.1 \pm 2.7 \mathrm{~cm}$ $\mathrm{H}_{2} \mathrm{O}$, that across the microvessels was $3.4 \pm 1.2 \mathrm{~cm} \mathrm{H}_{2} \mathrm{O}$, and that across the veins was $3.4 \pm 1.5 \mathrm{~cm} \mathrm{H}_{2} \mathrm{O}$. The major fraction of the total pressure drop was in arteries $(51 \%) ; 24.5 \%$ of the pressure drop was in microvessels and $24.5 \%$ in veins. As flow was constant, the fractional pressure drop represented fractional resistance of the pulmonary circulation.

Effect of elimination of vascular tone with papaverine on lung microvascular pressure profile in 3-to 4-wk-old rabbits. With the addition of papaverine, pulmonary artery pressure fell by an average of $1 \mathrm{~cm} \mathrm{H}_{2} \mathrm{O}$ (Table 2). Arteriolar and venular pressures were unchanged. Total pulmonary vascular resistance fell slightly but significantly from $0.097 \pm 0.02$ to $0.090 \pm 0.02 \mathrm{~cm} \mathrm{H}_{2} \mathrm{O}$. $\mathrm{min} \cdot \mathrm{ml}^{-1} \cdot \mathrm{kg}$; mainly due to a small decrease in resistance of the arterial segment $(p<0.01)$.

Table 1. Pulmonary vascular pressures in nine 3- to 4-wk-old rabbits (mean $\pm S D$ )*

\begin{tabular}{|c|c|c|c|c|c|c|c|}
\hline & \multirow{2}{*}{$\begin{array}{l}\text { Pulmonary } \\
\text { artery }\end{array}$} & & \multirow{2}{*}{$\frac{\text { Arteriole }(15) \dagger}{20-50 \mu \mathrm{m}}$} & & \multirow{2}{*}{$\frac{\text { Venule (9) } \dagger}{20-50 \mu \mathrm{m}}$} & & \multirow[b]{2}{*}{ Left atrium } \\
\hline & & & & & & & \\
\hline Pressureł $\left(\mathrm{cm} \mathrm{H}_{2} \mathrm{O}\right)$ & $21.8 \pm 2.3$ & & $14.7 \pm 1.4$ & & $11.3 \pm 0.9$ & & $8.0 \pm 0.0$ \\
\hline $\begin{array}{l}\text { Pressure drop in vascular seg- } \\
\text { ments }\left(\mathrm{cm} \mathrm{H}_{2} \mathrm{O}\right)\end{array}$ & & 7.1 & & 3.4 & & 3.4 & \\
\hline $\begin{array}{l}\text { \% of total pressure drop in vas- } \\
\text { cular segments }\end{array}$ & & 51 & & 24.5 & & 24.5 & \\
\hline
\end{tabular}

* Blood flow was $145 \pm 18 \mathrm{ml} / \mathrm{kg}$ body wt $/ \mathrm{min}$, pulmonary vascular resistance being $0.096 \pm 0.01 \mathrm{~cm} \mathrm{H}_{2} \mathrm{O} \cdot \mathrm{min} \cdot \mathrm{ml}{ }^{-1} \cdot \mathrm{kg}$.

$\dagger$ No. of punctured vessels.

$\ddagger$ Pressures in $\mathrm{cm} \mathrm{H}_{2} \mathrm{O}$, relative to pleural pressure (atmospheric) at level of micropuncture.

Table 2. Pulmonary vascular pressures in four 3- to 4-wk-old rabbits before and after addition of papaverine to perfusate $($ mean $\pm S D)$

\begin{tabular}{|c|c|c|c|c|c|c|c|c|c|}
\hline \multirow[b]{3}{*}{ Condition } & \multirow{3}{*}{$\begin{array}{l}\text { Pulmonary } \\
\text { vascular } \\
\text { resistance }\end{array}$} & & \multicolumn{7}{|c|}{ Pressures $\left(\mathrm{cm} \mathrm{H}_{2} \mathrm{O}\right)^{*}$} \\
\hline & & & \multirow{2}{*}{\multicolumn{2}{|c|}{$\begin{array}{c}\text { Pulmonary } \\
\text { artery }\end{array}$}} & \multirow{2}{*}{$\frac{\text { Arteriole }}{20-50 \mu \mathrm{m}}$} & & \multirow{2}{*}{$\frac{\text { Venule }}{20-50 \mu \mathrm{m}}$} & & \multirow[b]{2}{*}{ Left atrium } \\
\hline & & & & & & & & & \\
\hline & $\begin{array}{l}\mathrm{cm} \mathrm{H}_{2} \mathrm{O} \cdot \mathrm{min} \\
\mathrm{ml}^{-1} \cdot \mathrm{kg}\end{array}$ & & & & & & & & \\
\hline Before papaverine & $\begin{array}{r}0.097 \\
\pm 0.020\end{array}$ & & $\begin{array}{r}21.0 \\
\pm 1.3\end{array}$ & & $\begin{array}{l}14.5(8) \dagger \\
\pm 1.6\end{array}$ & & $\begin{array}{l}11.4(4) \dagger \\
\pm 1.2\end{array}$ & & $\begin{array}{r}8.0 \\
\pm 0.0\end{array}$ \\
\hline \multirow[t]{2}{*}{ After papaverine } & $\begin{aligned} & 0.090 \S \\
\pm & 0.020\end{aligned}$ & $\Delta \mathrm{p} \ddagger$ & $\begin{array}{l}19.8 \S \\
\pm 1.3\end{array}$ & 6.5 & $\begin{array}{l}14.4(8) \dagger \\
\pm 1.0\end{array}$ & 3.1 & $\begin{array}{l}11.4(4) \dagger \\
\pm 4.1\end{array}$ & 3.4 & $\begin{array}{r}8.0 \\
\pm 0.0\end{array}$ \\
\hline & & $\triangle \mathrm{p}$ & & 5.4 & & 3.0 & & 3.4 & \\
\hline
\end{tabular}

* Pressures in $\mathrm{cm} \mathrm{H}_{2} \mathrm{O}$, relative to pleural pressure (atmospheric) at level of micropuncture. Blood flow was constant at $133 \pm 31 \mathrm{ml} / \mathrm{kg}$ body wt/ $\min$.

$\dagger$ No. of punctured vessels.

$\ddagger$ Pressure drop in vascular segments.

$\S p<0.01$. 


\section{DISCUSSION}

Segmental vascular resistance in the lung. It is of interest to know the distribution of resistance in the pulmonary arteries, microvessels, and veins in order to understand fully the hemodynamics of the pulmonary circulation, to estimate the capillary filtration pressure, and to identify those vascular segments that undergo a change in caliber after a particular intervention. It is also important that we do not extrapolate data derived from the adult pulmonary vascular bed to the younger animal as the distribution of vascular resistance and the vascular reactivity may be different in the neonatal and juvenile lung from that of the adult lung.

In the 3- to 4-wk-old juvenile rabbit (rabbits are adults at approximately $12 \mathrm{wk}$ of age) we found that $\sim 50 \%$ of the total arteriovenous pressure drop was in arteries up to $20 \mu \mathrm{m}$ in diameter, $\sim 25 \%$ in microvessels $<20 \mu \mathrm{m}$ in diameter, and $\sim 25 \%$ in veins $>20 \mu \mathrm{m}$ in diameter. This distribution did not change appreciably after paralysis of vascular smooth muscle. This is in contrast to the lower arterial resistance (33\%) and practically no resistance in the veins $(\sim 7 \%)$ in the adult rabbit lung, with paralyzed vasculature (7).

Comparison between adult and 3- to 4-wk-old rabbit lungs. Segmental vascular resistance in the lung is influenced by lung volume, vascular transmural pressures, degree of vasomotor tone, and the rheological properties of blood. In addition, the geometry of the vascular bed, i.e. the branching pattern and caliber of the vessels and the viscoelastic properties of the vessel wall itself will affect the distribution of resistances in the lung (19). Hence, while comparing data from different studies, these factors must be considered. In our previous studies in adult rabbits, the lungs were kept inflated at $6 \mathrm{~cm} \mathrm{H}_{2} \mathrm{O}$ airway pressure, which is at approximately $65-70 \%$ of total lung capacity, similar to the lung volume at which we studied the 3- to 4-wk-old rabbits. The total arteriovenous pressure drop ranged between $10-13 \mathrm{~cm} \mathrm{H}_{2} \mathrm{O}$ and the lungs were perfused in zone III, conditions similar to that in the present study. The vasculature of the adult rabbit lungs was paralyzed with papaverine. The average hematocrit of the perfusate in the previous study was $22 \%$, similar to that in the present study. Hence, the differences seen in the distribution of segmental vascular resistance between the adult and 3- to 4-wkold rabbit lungs are probably due to the differences in vessel geometry, i.e. in the length of the vessels, the caliber of the vessels, and the viscoelastic properties of the vessel walls. With the continued growth of alveoli after birth, arterial size and numbers also increase (20). However, the amount of smooth muscle in the media of the vessel walls, especially in the small muscular arteries, progressively decreases after birth $(21,22)$. The thick medial coat in the arteries of the younger animals results in a smaller vessel lumen in relation to the external diameter of the vessel (23). This may be the cause of the higher arterial and venous resistance in lungs of younger animals. In the rabbit, with age, it appears as if pulmonary vascular resistance decreases mainly due to a decrease in resistance in the arteries and veins.

In the adult lung, basal vasomotor tone is very low, unlike that in the fetus and newborn (12). The basal vasomotor tone in the pulmonary circulation is probably maintained by circulating vasoactive agents (24), the autonomic nervous system playing little or no role (13). We found that there was little baseline vasomotor tone in the isolated perfused 3- to 4-wk-old rabbit lungs.

Comparison with data from other studies. As the conditions of the experiments vary with different studies, it is difficult to make a comparison among estimates of segmental vascular resistance in lungs by different investigators. In the studies using indirect methods (1-4) a major fraction of the resistance in the lung has been assigned to arteries. Using small catheters, Michel et al. (25) measured pressures in arteries and veins $<2 \mathrm{~mm}$ in diameter in the dog lung and found that arteries and veins $>1.2 \mathrm{~mm}$ in diameter impose 29 and $44 \%$, respectively, of the total resistance of the lung. In general the effective microvascular filtration pressure is assumed to be equal to the left atrial pressure plus 0.4 times the pulmonary artery-left atrial pressure difference, based on the observation of Gaar et al. (3) that approximately $60 \%$ of the total arteriovenous pressure drop was upstream and approximately $40 \%$ was downstream from the midpoint of the circulation. Our data in the 3- to 4-wk-old rabbits, also assign a major fraction of the resistance to the arteries, and the use of the formula of Gaar et al. (3) for the calculation of the microvascular filtration pressure would not be amiss. However, in the case of adult rabbit, this may underestimate the capillary filtration pressure because only $33 \%$ of the total resistance is in arteries.

Micropuncture measurement of microvascular pressure in isolated, perfused lungs. In an isolated perfused lung preparation, we can keep variables such as blood flow, lung volume, and outflow pressure constant. In intact animals, a stimulus, such as hypoxia, results in an increase in both pulmonary arterial pressure and blood flow to the lung, and because of the relationship between flow and resistance in the lung, it is difficult to separate active changes in vascular tone from passive flow-induced changes in vascular tone, making study of the pulmonary circulation difficult. A major advantage of the micropuncture technique is that it is the only method by which a direct measurement of microvascular pressures can be obtained. All previous measurements have been indirect and largely inferential. We can also determine the size and location of the vessels in which pressure measurements are obtained and thus define the anatomical boundaries of the vascular segments in the pulmonary circulation. A criticism of the technique is that because of the superficial location of the pressure measurements, the microvascular pressures obtained in the subplerual microcirculation may not represent pressures in the body of the lung. However, under conditions of homogenous blood flow, inflation, and water content such as in a nonedematous lung perfused under zone III conditions, the microvascular pressure profile measured in the subpleural microcirculation is probably representative of the whole lung $(7,26,27)$.

In summary, we have used the technique of lung micropuncture to determine the microvascualr pressure profile in lungs of 3- to 4-wk-old rabbits. The determination of segmental vascular resistance in the pulmonary circulation by lung micropuncture in neonatal and juvenile rabbits should prove useful in the study of pulmonary vascular responses to various stimuli.

Acknowledgments. The authors thank P. Barrette and $\mathrm{M}$. Towles for typing the manuscript.

\section{REFERENCES}

1. Agostini E, Piper J 1962 Capillary pressure and distribution of vascular resistance in isolated lung. Am J Physiol 202:1032-1036

2. Brody JS, Stemmler EJ, Dubois B 1968 Longitudinal distribution of vascular resistance in the pulmonary arteries, capillaries and veins. $\mathbf{J}$ Clin Invest 47:783-799

3. Gaar KAJ, Taylor AE, Owens LJ, Guyton AC 1967 Pulmonary capillary pressure and filtration coefficient in the isolated perfused lung. Am J Physiol 213:910-914

4. Hakim TB, Michel RP, Chang HK 1982 Partitioning of pulmonary vascular resistance in dogs by arterial and venous occlusion. J Appl Physiol 53:11101115

5. Bhattacharya J, Staub NC 1980 Direct measurement of microvascular pressures in the isolated perfused dog lung. Science 210:327-328

6. Bhattacharya J, Overholser K, Gropper MA, Staub NC 1982 Comparison of pressures measured by micropuncture and venous occlusion in zones II and III of the isolated dog lung. Fed Proc 41:1685 (abstr)

7. Raj JU, Bland RD, Lai-Fook SJ 1986 Microvascular pressures measured by micropipettes in isolated edematous rabbit lungs. J Appl Physiol 60:539545

8. Cassin S, Dawes GS, Ross BB 1962 Pulmonary blood flow and vascular resistance in immature fetal lambs. J Physiol (Lond) 171:80-89

9. Dawes GS, Mott JC 1962 The vascular tone of the fetal lung. J Physiol (Lond) $164: 465-477$

10. Cook CD, Drinker PA, Jacobsen HN, Larson H, Strang LB 1963 Control of 


\section{LUNG MICROVASCULAR PRESSURES IN YOUNG RABBITS}

pulmonary blood flow in the fetal and newly born lamb. $J$ Physiol (Lond) 169:10-29

11. Dawes GS, Mott JC, Widdicombe JG, Wyatt DG 1953 Changes in the lungs of the newborn lamb. J Physiol (Lond) 121:141-162

12. Rudolph AM 1979 Fetal and neonatal pulmonary circulation. Ann Rev Physiol 41:383-395

13. Colebatch HJH, Dawes GS, Goodwin JW, Nadeau RA 1965 The nervous control of the circulation in the fetal and newly expanded lungs of the lambs. J Physiol (Lond) 178:544-562

14. Davies G, Reid L 1970 Growth of the alveoli and pulmonary arteries in childhood. Thorax 25:669-681

15. West JB, Dollery CT, Naimark A 1964 Distribution of blood flow in isolated lung: relation to vascular and alveolar pressures. J Appl Physiol 19:713-724

16. Wiederhelm CA, Woodbury JW, Kirk S, Rushmer RF 1964 Pulsatile pressure in the circulation of frog's mesentery. Am J Physiol 207:173-176

17. Neutze JM, Wyler F, Rudolph AM 1968 Changes in distribution of cardiac output after hemorrhage in rabbits. Am J Physiol 215:857-864

18. Hauge A, Lunde PKM, Waaler BA 1966 Vasoconstriction in isolated blood perfused rabbit lungs and its inhibition by cresols. Acta Physiol Scand $66: 226-240$
19. Dawson CA 1984 Role of pulmonary vasomotion in physiology of the lung. Physiol Rev 64:544-616

20. Haworth SG, Hislop AA 1983 Pulmonary vascular development: normal values of peripheral vascular structure. Am J Cardiol 52:578-583

21. Hislop A, Reid L 1973 Pulmonary arterial development during childhoodbranching pattern and structure. Thorax 28:129-135

22. Naeye RL 1961 Arterial changes during the perinatal period. Arch Pathol $71: 121-128$

23. Wagenvoort CA, Neufeld HN, Edwards JE 1961 The structure of the pulmonary arterial tree in fetal and early postnatal life. Lab Invest 10:751-762

24. Soifer SJ, Loitz RD, Roman C, Heymann MA 1985 Leukotriene end organ antagonists increase pulmonary blood flow in fetal lambs. Am J Physio 249(Heart Cir Physiol 18):H570-H576

25. Michel RP, Hakim TS, Chang HK 1984 Pulmonary arterial and venous pressures measured with small catheters in dogs. J Appl Physiol 57:309-314

26. Linehan JH, Dawson CA, Rickaby DA 1982 Distribution of vascular resistance and compliance in a dog lung lobe. J Appl Physiol 54:158-168

27. Overholser KA, Bhattacharya J, Staub NC 1982 Microvascular pressures in isolated perfused dog lung. Comparison between theory and measurement. Microvasc Res 23:67-76 